Table 1. Correlations between a) BL RAMRIS and BL RAMRIQ tenosynovitis and CIS vs BL DAS28-4(CRP) $(\mathrm{N}=109)$ and b) $\triangle R A M R I S$ and $\triangle$ RAMRIQ tenosynovitis and $\mathrm{ClS}$ at M12 vs $\triangle \mathrm{DAS28}-4$ (CRP) at M12 $(\mathrm{N}=73)$ across treatment arms ${ }^{\mathrm{a}}$

\begin{tabular}{|c|c|c|c|c|c|}
\hline & BL DAS28-4 & (CRP) & & $\triangle D A S 28-4(C$ & RP) \\
\hline BL imaging feature & Correlation & $p$ value & $\Delta$ Imaging feature & Correlation & p val \\
\hline $\begin{array}{l}\text { RAMRIS } \\
\text { tenosynovitis }\end{array}$ & 0.366 & 0.0001 & $\begin{array}{l}\text { RAMRIS } \\
\text { tenosynovitis }\end{array}$ & 0.531 & 0.00 \\
\hline RAMRIS CIS & 0.399 & $<0.0001$ & RAMRIS CIS & 0.554 & $<0.00$ \\
\hline $\begin{array}{l}\text { RAMRIQ } \\
\text { tenosynovitis }\end{array}$ & 0.205 & 0.037 & $\begin{array}{l}\text { RAMRIQ } \\
\text { tenosynovitis }\end{array}$ & 0.543 & $<0.00$ \\
\hline RAMRIQ CIS & 0.180 & 0.062 & RAMRIQ CIS & 0.564 & $<0.000$ \\
\hline
\end{tabular}

${ }^{a}$ Data were pooled across the tofacitinib $10 \mathrm{mg} \mathrm{BID} \pm$ MTX and MTX monotherapy armsSpear man's rank correlation coefficients and $p$ values were calculated for associations between RAMRIS and RAMRIQ parameters and DAS28-4(CRP); tenosynovitis and CIS were assessed using combined data from metacarpophalangeal and wrist joints; CIS is the sum of synovitis, $\mathrm{BME}$ and tenosynovitis values $\Delta$, change from $\mathrm{BL} ; \mathrm{N}$, number of pts with values at BL/timepoint of interest

Conclusion: Responsiveness of RAMRIS and RAMRIQ tenosynovitis and CIS was demonstrated with significant improvements through M12 in pts receiving tofacitinib $10 \mathrm{mg} \mathrm{BID} \pm$ MTX vs MTX. Construct validity for RAMRIS and RAMRIQ tenosynovitis and CIS was evident from correlations with DAS28-4(CRP). Further work is needed to validate these novel imaging biomarkers in terms of relative responsiveness and prediction of later structural progression.

REFERENCES:

[1] Conaghan et al. Ann Rheum Dis 2016; 75: 1024-1033.

Acknowledgements: Study sponsored by Pfizer Inc. Medical writing support was provided by Jennifer Arnold, CMC Connect, and funded by Pfizer Inc.

Disclosure of Interests: Philip G Conaghan Speakers bureau: AbbVie, Novartis, Consultant of: AbbVie, Bristol-Myers Squibb, Eli Lilly, Flexion, Galapagos, Gilead Sciences, GlaxoSmithKline, Janssen, Novartis, Pfizer Inc, Regeneron, Mikkel Østergaard Speakers bureau: AbbVie, Boehringer Ingelheim, Bristol-Myers Squibb, Celgene, Centocor, Eli Lilly, GlaxoSmithKline, Hospira, Janssen, Merck, Mundipharma, Novartis, Novo, Orion, Pfizer Inc, Regeneron, Roche, Schering-Plough, Takeda, UCB, Wyeth, Consultant of: AbbVie, Boehringer Ingelheim, Bristol-Myers Squibb, Celgene, Centocor, Eli Lilly, GlaxoSmithKline, Hospira, Janssen, Merck, Mundipharma, Novartis, Novo, Orion, Pfizer Inc, Regeneron, Roche, Schering-Plough, Takeda, UCB, Wyeth, Grant/research support from: AbbVie, Centocor, Merck, Orrin Troum Speakers bureau: AbbVie, Amgen, Bristol-Myers Squibb, Celgene, Horizon, Novartis, Pfizer Inc, Sanofi-Genzyme, Consultant of: AbbVie, Amgen, Bristol-Myers Squibb, Eli Lilly, Horizon, Pfizer Inc, Grant/research support from: AbbVie, Amgen, Bristol-Myers Squibb, Centocor, Corrona, Novartis, Pfizer Inc, Zhiyong Xie Shareholder of: Pfizer Inc, Employee of: Pfizer Inc, Alan Brett Shareholder of: Stryker Corp, Employee of: Stryker Corp, Mark Snyder Shareholder of: Pfizer Inc, Employee of: Pfizer Inc, Abbas Ebrahim Shareholder of: Pfizer Inc, Employee of: Pfizer Inc, Douglass Chapman Shareholder of: Pfizer Inc, Employee of: Pfizer Inc, Gosford Sawyerr Consultant of: Pfizer Inc, Employee of: Syneos Health, John Andrews Shareholder of: Pfizer Inc, Employee of: Pfizer Inc

DOI: 10.1136/annrheumdis-2021-eular.364

\section{POS0444 \\ DIAGNOSTIC VALUE OF HIGH-RESOLUTION PERIPHERAL QUANTITATIVE COMPUTED TOMOGRAPHY COMPARED TO CONVENTIONAL RADIOGRAPHY FOR DETECTING EROSIVE DISEASE IN RHEUMATOID ARTHRITIS}

R. Klose-Jensen ${ }^{1,2}$, J. Therkildsen ${ }^{1,2}$, A. B. Blavnsfeldt ${ }^{1}$, B. Langdahl ${ }^{3}$, K. K. Keller ${ }^{2}$, E. M. Hauge ${ }^{1,2} .{ }^{1}$ Aarhus University Hospital, Department of Rheumatology, Aarhus N, Denmark; ${ }^{2}$ Aarhus University, Department of Clinical Medicine, Aarhus N, Denmark: ${ }^{3}$ Aarhus University Hospital, Department of Endocrinology and Internal Medicine, Aarhus N, Denmark

Background: Conventional radiography $(\mathrm{CR})$ of the hands, wrists and feet is currently the gold standard for assessing erosive damage in patients with rheumatoid arthritis (RA). However, CR is prone to relatively low resolution and projection superimposition due to 2-dimensional imaging. Therefore, CR might not detect erosive disease in RA patients. High-resolution peripheral quantitative computed tomography (HR-pQCT) is an imaging modality with superior resolution $\left(82 \mu \mathrm{m}^{3}\right)$ to all other imaging modalities in vivo. However, HR-pQCT imaging is limited by a smaller field of view. Therefore, it needs to be illuminated, whether the higher resolution of HR-pQCT imaging is sufficient for diagnosing erosive disease in patients with RA despite the limited field of view.

Objectives: The objective was to investigate whether High-Resolution peripheral Quantitative Computed Tomography (HR-pQCT) of just two metacarpophalangeal (MCP) joints can diagnose more patients having erosive RA than conventional radiography (CR) of 44 joints in the hands, wrist and feet.

Methods: In this single-centre cross-sectional study. Patients with established RA (disease duration $\geq 5$ years) were investigated by HR-pQCT and CR. The second and third MCP joints of the dominant hand were assessed for erosions by HR-pQCT. CR in the hands, wrist and feet were scored according to the Sharp/ van der Heijde (SHS) method.

Results: Three hundred fifty-four patients were included. By CR, 67 (18.9\%) patients were classified with non-erosive RA, and $287(81.1 \%)$ with erosive RA In the 67 patients with non-erosive RA, 47 patients $(70.1 \%)$ had erosions in the second and third MCP joints by HR-pQCT (Figure 1). We found an agreement between CR and HR-pQCT for $274(77.4 \%)$ of the patients. The sensitivity and specificity $(95 \% \mathrm{Cl})$ of $\mathrm{HR}$-pQCT for diagnosing erosive RA when CR of hands, wrist and feet were used as the reference was $89 \%(84-92) \%$ and $30 \%(19$ - 42) \%, respectively. Using HR-pQCT for two MCP joints as the reference, the sensitivity and specificity of $\mathrm{CR}$ of hands, wrist and feet for diagnosing erosive RA were $84 \%(80-88) \%$ and $38 \%(25-52) \%$, respectively. The McNemar's $\chi^{2}$ test for diagnosing patients having erosive RA between the two modalities was $2.45, p=0.146$

Conclusion: HR-pQCT imaging identifies erosions which are not seen by $\mathrm{CR}$. Using HR-pQCT at of the second and third MCP joint reclassified a substantial number of patients as having erosive RA compared to their non-erosive state determined by $\mathrm{CR}$. The sensitivity and specificity of diagnosing patients having erosive RA using HR-pQCT from only two fingers were not statistically different from $\mathrm{CR}$ of 44 joints, in the hands, wrist and feet.

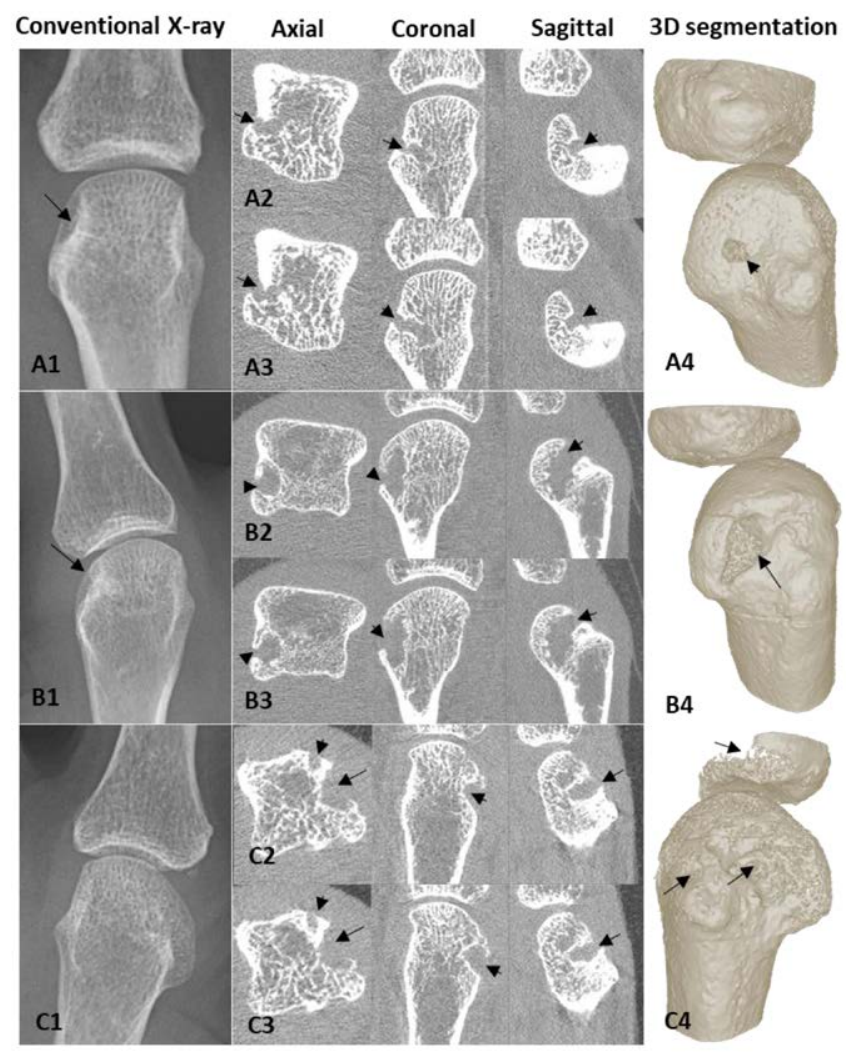

Acknowledgements: The authors, we want to acknowledge Aarhus University, The Danish Rheumatism Association, Novo Nordic Foundation and A.P. Møller Fonden who have financially supported the study. The funding sources did not have any role in the collection, analysis and interpretation of data. The authors are grateful for the excellent assistance in recruiting and scheduling the patients by Mia Marie Remmer, Lone Thomasen and Else Sloth Rousing.

Disclosure of Interests: Rasmus Klose-Jensen: None declared, Josephine Therkildsen: None declared, Anne-Birgitte Blavnsfeldt: None declared, Bente 
Langdahl Speakers bureau: Eli Lilly, Amgen, UCB, Gilead, and Gideon-Richter, Grant/research support from: Novo Nordisk and Amgen, Kresten Krarup Keller: None declared, Ellen-Margrethe Hauge Speakers bureau: MSD, Pfizer, UCB, and Sobi., Grant/research support from: Roche, Novartis and Novo Nordic Foundation.

DOI: 10.1136/annrheumdis-2021-eular.519

\begin{tabular}{|l|l}
\hline POS0445 & PHYSICIAN AND PATIENT REPORTED \\
& EFFECTIVENESS OUTCOMES ARE \\
& SIMILAR IN TOFACITINIB AND TNF INHIBITORS IN \\
& RHEUMATOID ARTHRITIS PATIENTS: DATA \\
& FROM A RHEUMATOID ARTHRITIS REGISTRY IN \\
& CANADA
\end{tabular}

M. Movahedi ${ }^{1}$, A. Cesta ${ }^{1}$, X. Li $\mathrm{Li}^{1}$, E. Keystone ${ }^{2}$, C. Bombardier ${ }^{1}$ on behalf of OBRI investigators. ${ }^{1}$ UHN, Toronto General Hospital Research Institute, Toronto, Canada; ${ }^{2}$ University of Toronto, Medicine, Toronto, Canada

Background: Tofacitinib (TOFA) is an oral, small molecule drug used for rheumatoid arthritis (RA) treatment as an alternative option to biologic disease modifying antirheumatic drugs (bDMARDs) including tumor necrosis factor inhibitors (TNFi).

Objectives: We aimed to evaluate physician and patient reported effectivness outcomes in TNFi compared to TOFA, using real-world data from the Ontario Best Practices Research Initiative (OBRI).

Methods: RA patients enrolled in the OBRI initiating their TOFA or TNFi (Adalimumab, Certolizumab, Etanercept, Golimumab, Infliximab, and Biosimilars) between $1^{\text {st }}$ June 2014 (TOFA approval date in Canada) and $31^{\text {st }}$ Dec 2019 were included. Patients were required to have physician and patient reported effectivness outcomes data available at treatment initiation and 6-month ( \pm 2 months) follow-up. These included clinical disease activity index (CDAI), rheumatoid arthritis disease activity index (RADAI), HAQ-DI, sleep problem, and anxiety/ depression scores. Multiple imputation (Imputation Chained Equation, $\mathrm{N}=20$ ) was used to deal with missing data for covaraites at treatment initiation. To dea with confounding by indication, we estimated propensity scores for covariates with an absolute standard difference greater than 0.1 between the two treatment groups.

Results: A total of 419 patients were included. Of those, 226 were initiating a TNFi and 193 TOFA, and had a mean (SD) disease duration of 8.0 (8.7) and 12.6 (9.6) years, respectively. In the TNFi group, $81.9 \%$ were female and mean age (SD) at treatment initiation was 56.6 (13.4) years. In the TOFA group, $85 \%$ were female and mean (SD) age at treatment initiation was 60.3 (11.2) years. The TNFi group was less likely to have prior biologic use $(21.7 \%)$ compared to the TOFA group (67.9\%). At treatment initiation, physical function measured by HAQ-DI was significantly lower in TNFi compared to the TOFA group (1.2 vs.1.4).

The rate of CDAI LDA/remission at 6 months was $36.7 \%$ and $33.2 \%$ in TNFi and TOFA group, respectively. The generalized linear mixed models (GLMM) adjusting for propensity score quantile, showed that there was no significant difference in CDAI LDA/remission (ORs: $0.85,95 \% \mathrm{Cl}$ : 0.51, 1.43), RADAI (coefficient: 0.48, 95\% Cl: $-0.18,1.14)$, HAQ-DI (coefficient: $-0.01,95 \% \mathrm{Cl}:-0.18,0.16$ ), sleep problems (coefficient: $-0.25,95 \% \mathrm{Cl}:-0.95,0.45$ ), and anxiety/depression scores (coefficient: $0.12,95 \% \mathrm{Cl}:-0.35,0.58$ ) between the two treatment groups (TOFA used as reference)

Conclusion: In this real-world data study, we found that, physician and patient reported effectivness outcomes are similar in the TNFi and TOFA groups 6 months after treatment initiation in patients with RA

Disclosure of Interests: Mohammad Movahedi: None declared, Angela Cesta: None declared, Xiuying Li: None declared, Edward Keystone Grant/ research support from: Amgen, Merck, Pfizer Pharmaceuticals, PuraPharm. Speaker Honoraria Agreements: AbbVie, Amgen, Bristol-Myers Squibb Company, Celltrion, Myriad Autoimmune, F. Hoffmann-La Roche Inc, Gilead, Janssen Inc, Lilly Pharmaceuticals, Merck, Pfizer Pharmaceuticals, Sandoz, Sanofi-Genzyme, Samsung Bioepsis. Consulting Agreements/Advisory Board Membership: AbbVie, Amgen, Bristol-Myers Squibb Company, Celltrion, Myriad Autoimmune, F. Hoffmann-La Roche Inc, Gilead, Janssen Inc, Lilly Pharmaceuticals, Merck, Pfizer Pharmaceuticals, Sandoz, Sanofi-Genzyme, Samsung Bioepsis, Claire Bombardier Grant/research support from: OBRI was funded by peer reviewed grants from CIHR (Canadian Institute for Health Research), Ontario Ministry of Health and Long-Term Care (MOHLTC), Canadian Arthritis Network (CAN) and unrestricted grants from: Abbvie, Amgen, Aurora, Bristol-Meyers Squibb, Celgene, Hospira, Janssen, Lilly, Medexus, Merck, Novartis, Pfizer, Roche, Sanofi, \& UCB. Dr. Bombardier held a Canada Research Chair in Knowledge Transfer for Musculoskeletal Care and a Pfizer Research Chair in Rheumatology DOI: 10.1136/annrheumdis-2021-eular.787

\section{\begin{tabular}{|l|l}
\hline POS0446 FILGOTINIB-TREATED RHEUMATOID ARTHRITIS \\
\hline
\end{tabular} PATIENTS WITH HIGH BASELINE NEUTROPHIL-TO- LYMPHOCYTE RATIO SHOW BETTER CLINICAL RESPONSE RATES AND PATIENT-REPORTED OUTCOMES}

P. C. Taylor ${ }^{1}$, B. Downie ${ }^{2}$, S. Kim², R. Hawtin ${ }^{2}$, R. Moots ${ }^{3}$, T. Takeuchi ${ }^{4}$. ${ }^{1}$ University of Oxford, Botnar Research Centre, Nuffield Dept Orthopaedics, Rheumatology and Musculoskeletal Sciences, Oxford, United Kingdom; ${ }^{2}$ Gilead Sciences, Inc., Foster City, United States of America; ${ }^{3}$ Edge Hill University, Faculty of Health, Social Care and Medicine, Ormskirk, United Kingdom; ${ }^{4}$ Keio University School of Medicine, Division of Rheumatology, Department of Internal Medicine, Tokyo, Japan

Background: Rheumatoid arthritis (RA) is a systemic inflammatory disease which includes increased innate and myeloid immune cell activation. Filgotinib (FIL), an oral JAK1 inhibitor, has shown safety and efficacy in three phase 3 studies (FINCH1-3) in adults with moderately-to-severely active RA. The baseline $(\mathrm{BL})$ neutrophil-to-lymphocyte ratio (NLR) in RA has been associated with a positive response to anti-tumor necrosis factor (TNF) therapy ${ }^{1}$ and a negative response to DMARD triple therapy ${ }^{2}$. We previously reported a $\mathrm{BL}$ signature of clinical response in the FINCH2 (bDMARD-IR) population which included a neutrophil component ${ }^{3}$.

Objectives: We conducted a post-hoc analysis to explore whether the BL NLR was associated with response to treatment in the $\mathrm{FINCH}$ studies.

Methods: Clinical data of 3273 RA patients (pts) enrolled in the FINCH clinical trials (FINCH3, methotrexate (MTX)-naïve: NCT02886728; FINCH1, MTX-Inadequate Responder (IR): NCT02889796; FINCH2, bDMARD-IR: NCT02873936) were retrospectively analyzed for a relationship between the BL NLR and composite clinical endpoints (ACR-N, DAS28CRP, or CDAI) or PROs (Pain VAS FACIT Fatigue, HAQ-DI) through week 24. Pts were classified as High or Low BL NLR using a cutpoint (2.7) identified as an independent predictor of treatment failure in a published RA study ${ }^{2}$. Adjusted clinical outcomes were estimated based on mixed effects linear regression models including geographic region and demographics covariates.

Results: $57 \%$ of pts enrolled in the FINCH trials were classified as BL NLR-High (Table 1) and FINCH3 NLR-High pts showed higher BL DAS28(CRP). FINCH1 and FINCH3 FIL+MTX-arm NLR-High pts demonstrated significantly better DAS28(CRP) response compared to NLR-Low pts (Figure 1). DAS28(CRP) differences between NLR-High and NLR-Low were detectable as early as Week 2 for FIL200mg + MTX and were sustained through Week 24. FINCH1 and FINCH3 FIL200mg + MTX NLR-High pts also demonstrated sustained clinical and PRO improvements over NLR-Low, including CDAI, ACR-N, Pain VAS, FACIT Fatigue, and HAQ-DI. The strength of these associations was dose-dependent; pts that received FIL100mg + MTX demonstrated weaker but directionally consistent trends in both populations. No significant association between NLR subgroup and clinical efficacy was observed in FINCH2 FIL+MTX-arm pts, FIL-monotherapy (FINCH3) pts, or adalimumab+MTX (FINCH1) pts.

Conclusion: In FINCH1 (MTX-IR) and FINCH3 (MTX-naïve), FIL200mg + MTX -arm NLR-High pts demonstrate better sustained clinical response and PRO scores compared to NLR-Low pts. These data are the first to report an association between the BL NLR and therapeutic response in large randomized RA clinical trials. Future studies on pathobiologies reflected by the NLR biomarker may clarify its potential to guide RA disease management.

\section{REFERENCES:}

[1] Farutin V. Arthritis Res Ther. 2019.

[2] Boulos D. Semin Arthritis Rheum. 2019.

[3] Taylor P. Arthritis Rheumatol. 2019; 71 (suppl 10).

Table 1. Demographics of patients enrolled in FINCH clinical trials by baseline NLR category.

\begin{tabular}{lcccc}
\hline & $\begin{array}{c}\text { NLR-Low } \\
(\mathrm{NLR}<\mathbf{2 . 7}) \\
(\mathrm{N}=1407,43 \%)\end{array}$ & $\begin{array}{c}\text { NLR-High } \\
(\mathbf{N L R}>\mathbf{2 . 7}) \\
(\mathrm{N}=1866,57 \%)\end{array}$ & $\begin{array}{c}\text { Total } \\
(\mathrm{N}=3273,100 \%)\end{array}$ & P-value \\
\hline Age at enrollment & & & & $0.668^{2}$ \\
Mean (SD) & $53.00(12.74)$ & $53.19(13.24)$ & $53.11(13.02)$ & \\
$\begin{array}{l}\text { Female } \\
\text { Seropositivity }\end{array}$ & $1,157(82.2 \%)$ & $1,448(77.6 \%)$ & $2,605(79.6 \%)$ & $0.001^{1}$ \\
$\begin{array}{l}\text { Prior bDMARD \# } \\
\text { Mean (SD) }\end{array}$ & $1,073(76.3 \%)$ & $1,575(84.4 \%)$ & $2,648(80.9 \%)$ & $<0.001^{1}$ \\
$\begin{array}{l}\text { Duration of RA } \\
\text { Mean (SD) }\end{array}$ & $0.23(0.73)$ & $0.28(0.82)$ & $0.26(0.78)$ & $0.037^{2}$ \\
$\begin{array}{l}\text { Baseline oral corticosteroid } \\
\text { Baseline DAS28(CRP) }\end{array}$ & $5.93(7.39)$ & $6.61(8.07)$ & $6.32(7.79)$ & $0.013^{2}$ \\
Baseline HAQ-DI & $5.55(0.90)$ & $895(48.0 \%)$ & $1,432(43.8 \%)$ & $<0.001^{1}$ \\
\hline & $1.53(0.60)$ & $1.62(0.65)$ & $1.58(0.63)$ & $0.001^{2}$ \\
\hline
\end{tabular}

${ }^{1}$ Pearson's Chi-squared test. ${ }^{2}$ Linear Model ANOVA. 